\section{RMD Open}

Rheumatic \&

Musculoskeletal Diseases

\title{
Neutropaenia in early rheumatoid arthritis: frequency, predicting factors, natural history and outcome
}

George E Fragoulis, Caron Paterson, Ashley Gilmour, Mohammad H Derakhshan, lain B Mclnnes, Duncan Porter, Stefan Siebert

To cite: Fragoulis GE, Paterson C, Gilmour A, et al. Neutropaenia in early rheumatoid arthritis: frequency, predicting factors, natural history and outcome. RMD Open 2018:4:e000739. doi:10.1136/ rmdopen-2018-000739

- Prepublication history and additional material for this paper are available online. To view these files, please visit the journal online (http://dx.doi. org/10.1136/rmdopen-2018000739).

Received 4 June 2018 Revised 6 August 2018 Accepted 16 August 2018

\section{Check for updates}

(c) Author(s) (or their employer(s)) 2018. Re-use permitted under CC BY-NC. No commercial re-use. See rights and permissions. Published by BMJ.

Institute of Infection, Immunity and Inflammation, University of Glasgow, Glasgow, UK

Correspondence to Dr George E Fragoulis; geofragoul@yahoo.gr

\section{ABSTRACT}

Objectives To determine the frequency, severity and natural history of neutropaenia in early rheumatoid arthritis (RA), explore its associations with clinical features and assess its impact on clinical management.

Methods The Scottish Early Rheumatoid Arthritis inception cohort prospectively recruited patients with newly diagnosed RA and followed them up every 6 months. Patients with RA who developed at least one episode of neutropaenia (grade $1:<2.0 \times 10^{\wedge} \mathrm{g} / \mathrm{L}$; grade 2: $<1.5 \times 10^{\wedge} 9 / \mathrm{L}$; grade $3:<1.0 \times 10^{\wedge} 9 / \mathrm{L}$; grade 4 : $<0.5 \times 10^{\wedge}$ 9/L) were compared with those who did not. Comparisons were also made between patients who experienced one or more episodes of neutropaenia and between patients with different neutropaenia grades. Results 77 neutropaenia episodes were recorded in 58 of $771(7.5 \%)$ patients with RA, who were followed up for a median (range) of $18(6-48)$ months. Neutropaenia occurred at a median (range) of $12(0-120)$ months after RA diagnosis. The majority had mild neutropaenia (grade 1: $n=42$; grade 2 : $n=14$; grade $3: n=1$; grade $4: n=1$ ). Neutropaenia was transient (single episode) in the majority $(44 ; 75.8 \%)$ of cases but led to treatment discontinuation in $14(24.1 \%)$ patients. Patients who developed neutropaenia were more likely to be female $(p=0.01)$ and non-smokers $(p=0.007)$ and had lower baseline neutrophil levels $(p<0.0001)$. Binomial regression analysis confirmed the latter $(p<0.0001, B:-0.491)$ as neutropaenia predictor. The rate of infections did not differ between patients who developed neutropaenia and those who did not $(p=0.878)$. Conclusion Neutropaenia was a common finding in this cohort. It was usually mild, transient and not associated with increased infection rates. Neutropaenia occurrence was associated with non-smoking, female gender and lower baseline neutrophil levels.

\section{INTRODUCTION}

Neutropaenia is a recognised finding in the context of rheumatoid arthritis (RA). Surprisingly, its actual incidence and clinical impact have not been well described despite its rather common occurrence in routine care. ${ }^{1-4}$ There are various potential factors contributing to neutropaenia in RA, including drugs (conventional and biologic

\section{Key messages}

What is already known about this subject?

- Neutropaenia is a recognised finding in the context of rheumatoid arthritis (RA).

- However its frequency and characteristics are not well defined, particularly in early RA.

What does this study add?

- Neutropaenia is examined in a real-world early RA cohort with longitudinal follow-up.

- Frequency $(\sim 7.5 \%)$, predicting factors (low neutrophils at baseline, non-smoking, female gender), natural history (usually mild, possibly relating to medications) and outcome (not leading to increased rates of infections or other adverse outcomes) are described.

How might this impact on clinical practice?

- Careful monitoring of patients with early RA for neutropaenia is recommended, particularly those with adverse predicting factors.

disease-modifying antirheumatic drugs (DMARDs)), autoimmune mechanisms (eg, Felty's syndrome), coexistent viral infections, and other conditions like large granulocytic lymphocytic leukaemia. ${ }^{5} 6$ Relatively few studies have been published investigating the frequency of neutropaenia in RA. Most of these are for patients with RA treated with specific medications or retrospective database studies, ${ }^{134} 4$-14 while one study reported the prevalence of baseline neutropaenia in patients with untreated RA. ${ }^{2}$ To the best of our knowledge, no studies have examined the occurrence of neutropaenia in a national real-world inception cohort of patients with RA with longitudinal follow-up.

The aim of our study was first to determine the frequency and severity (grade) of neutropaenia in patients with early RA. Second, we wished to explore possible associations with clinical or laboratory manifestations and 
with conventional DMARDs treatment. We also aimed to investigate if there were any potential predictors for its occurrence. Finally, we explored the natural history of neutropaenia in RA (ie, transient or recurrent) and the effect on patients' management (permanent or temporal treatment discontinuation) and susceptibility to infections.

\section{PATIENTS AND METHODS \\ Cohort description}

Data were obtained from the Scottish Early Rheumatoid Arthritis (SERA) inception cohort, which prospectively recruited patients with new-onset RA and undifferentiated arthritis ( $\geq 1$ swollen joint) between 2011 and 2015 attending rheumatology centres across Scotland. ${ }^{15}$ Participants in SERA were treated by their usual rheumatology team as per standard clinical practice, independent of their participation in the cohort. This current study evaluated participants in SERA who fulfilled the American College of Rheumatology/European League Against Rheumatism (ACR/EULAR) 2010 criteria for $\mathrm{RA}^{16}$ at the baseline visit. Patients with an alternative autoimmune rheumatic diagnosis at baseline, patients whose diagnosis was revised to another rheumatic disease during follow-up or patients who had previously received any DMARD were excluded. ${ }^{15}$

A range of prespecified features were recorded at the baseline visit and then at 6-monthly follow-up visits, including clinical (coexistent medical conditions, medication being received for RA or other diseases), demographic (age, gender, height, weight, smoking status, alcohol consumption, employment status) and laboratory (full blood count, biochemistry profile, acute phase reactants, rheumatoid factor and anti-Cyclic Citrullinated Peptide (CCP) (assessed by fluorescence-based ELISA using second-generation CCP)) parameters and disease activity indices (Disease Activity Score in 28 joints (DAS28), Clinical Disease Activity Index (CDAI), Simple Disease Activity Index (SDAI)). Patients included in this study had at least two sets of laboratory results recorded, while those with no neutrophil count available were excluded. The baseline characteristics of the cohort have been previously described..$^{15}$ Written informed consent was obtained from all participants.

\section{Study design}

SERA participants with RA who developed at least one episode (defined as a data entry in SERA database) of neutropaenia (grade 1: $1.5-2.0 \times 10^{\wedge} 9 / \mathrm{L}$; grade 2: $1.5-1.0 \times 10^{\wedge} 9 / \mathrm{L}$; grade $3: 1.0-0.5 \times 10^{\wedge} 9 / \mathrm{L}$; grade 4 : $\left.<0.5 \times 10^{\wedge} 9 / \mathrm{L}\right)$ were identified. Their demographic, clinical and laboratory characteristics at baseline, as well as throughout the total follow-up time, were compared with those of patients with RA who never had a recorded episode of neutropaenia. Comparisons were also made between patients with a single recorded episode of neutropaenia (transient) and those who had more than one episode recorded (recurrent), and between patients with different grades of neutropaenia.

Leucopaenia was defined as a total white cell count $<4.0 \times 10^{\wedge} 9 / \mathrm{L} ;$ lymphopaenia as lymphocytes $<1.0 \times 10^{\wedge} 9 / \mathrm{L}$; thrombocytopaenia as platelets $<100 \times 10^{\wedge} 9 / \mathrm{L}$, and anaemia as haemoglobin $<120 \mathrm{~g} / \mathrm{L}$ for women and $<135$ $\mathrm{g} / \mathrm{L}$ for men. Total follow-up time was defined as the time interval between the time of the RA diagnosis and the last follow-up visit for the SERA study. Infections temporally associated with neutropaenia were defined as those recorded in the database occurring within 3 months prior to or after the recorded episode of neutropaenia.

\section{Statistics}

Two-sided Fisher's exact and Mann-Whitney tests were used to compare categorical and numerical characteristics, respectively. Benjamini-Hochberg correction was applied for multiple comparison correction for a false discovery rate of $0.25 .{ }^{17}$ In detail, Benjamini-Hochberg procedure was performed as follows: $p$ values of comparisons in the same category (eg, baseline laboratory characteristics from table 1) were placed in ascending order and a rank was assigned to each $p$ value, starting from the smallest $p$ value. Corrected $p$ value (also known as critical value) was calculated using the formula $(\mathrm{i} / \mathrm{m}) \mathrm{Q}$, where ' $\mathrm{i}$ ' is the rank of the $\mathrm{p}$ value, ' $\mathrm{m}$ ' the total number of tests and ' $Q$ ' the false discovery rate. In our study, this latter was preset to 0.25 . The largest $p$ value that was smaller than the critical value was then marked. All the values, smaller than the latter, were considered statistically significant. In our study, no significant $p$ value became insignificant after correction for multiple comparison. A binary logistic regression analysis (enter model) was performed using the occurrence of neutropaenia as the dependent variable, and 13 predefined clinical and laboratory features (age, gender, smoking status, alcohol consumption, seropositivity, baseline cytopaenias, baseline neutrophil number and treatment being received for RA) as independent variables. Patients with neutropaenia at the baseline visit $(n=5)$ were excluded from the latter analysis. Possible interaction between relevant variables (ie, smoking status by gender and smoking status by baseline neutrophil levels and gender by baseline neutrophil levels) was also checked. Statistical analysis was performed using SPSS V.21.0 software.

\section{RESULTS}

\section{Cohort description}

Of the total 913 patients with RA in SERA, 142 were excluded because of missing laboratory values, as described above. Seven hundred and seventy-one patients with RA (ACR/EULAR 2010 criteria) were available for evaluation, with follow-up data available for a median (range) time of 18 (6-48) months. Comparison of the excluded patients with the group of those included in the study did not reveal any differences (online supplementary table 1). The baseline characteristics of the 
Table 1 Baseline demographic and laboratory characteristics of patients with RA included in this data set

\begin{tabular}{|c|c|c|c|}
\hline Patient characteristics & $\begin{array}{l}\text { Neutropaenic } \\
n=58\end{array}$ & $\begin{array}{l}\text { Non-neutropaenic } \\
n=713\end{array}$ & P values \\
\hline \multicolumn{4}{|l|}{ Demographic } \\
\hline Age, ${ }^{\star}$ mean $\pm S D$ & $57.7 \pm 14.1$ & $58.8 \pm 13.4$ & 0.538 \\
\hline Female gender, n (\%) & $47(81.0)$ & $460(64.5)$ & 0.010 \\
\hline Total follow-up (months), median (range) & $18(6-48)$ & $18(6-48)$ & 0.139 \\
\hline Smoking, n (\%) & $6(10.3)$ & $188(26.4)$ & 0.007 \\
\hline Alcohol consumption, $\mathrm{n}(\%)$ & $40(69.0)$ & $421(57.9)$ & 0.127 \\
\hline \multicolumn{4}{|l|}{ Laboratory } \\
\hline Anaemia,† n (\%) & $7 / 55(12.7)$ & 142/702 (20.2) & 0.218 \\
\hline Thrombocytopaenia,‡ n (\%) & 0/55 (0.0) & 0/702 (0.0) & 1.000 \\
\hline Leucopaenia,§ n (\%) & $1 / 55(1.8)$ & 3/702 (0.4) & 0.261 \\
\hline Lymphopaenia, ๆ n (\%) & $4 / 55(7.2)$ & $40 / 702(5.7)$ & 0.520 \\
\hline Neutrophils number, mean \pm SD $\left(\times 10^{\wedge} 9 / L\right)^{\star \star}$ & $4.29 \pm 2.12$ & $5.89 \pm 2.15$ & $<0.0001$ \\
\hline RF-positive, n (\%) & 27/35 (77.1) & $284 / 428(67.1)$ & 0.262 \\
\hline Anti-CCP-positive, n (\%) & $35 / 46(74.4)$ & $410 / 587(69.8)$ & 0.620 \\
\hline Baseline DAS28, mean \pm SD & $4.76 \pm 1.51$ & $5.04 \pm 1.38$ & 0.310 \\
\hline
\end{tabular}

${ }^{*}$ Age at the time of RA diagnosis.

†Haemoglobin $<135 \mathrm{~g} / \mathrm{L}$ for men and haemoglobin $<120 \mathrm{~g} / \mathrm{L}$ for women.

$\ddagger$ Platelets $<100 \times 10^{\wedge} \mathrm{g} / \mathrm{L}$

§White cell count: $<4 \times 10^{9} / \mathrm{L}$.

|Lymphocytes: $<1 \times 10^{9} / \mathrm{L}$.

${ }^{* \star} n=53$ (5 patients had neutropaenia at baseline).

CCP, Cyclic Citrullinated Peptide; DAS28, Disease Activity Score in 28 joints; RA, rheumatoid arthritis; RF, rheumatoid factor.

participants included in the analysis, with and without at least one episode of neutropaenia, are shown in table 1.

\section{Neutropaenia frequency and severity}

A total of 77 episodes of neutropaenia were observed in 58 out of $771(7.5 \%)$ patients (giving a neutropaenia episode rate per 1000 person-months $(95 \% \mathrm{CI})$ of 4.94 (3.63 to 6.15)). None of these patients had a diagnosis of Felty's syndrome or large granulocytic leukaemia, were receiving medications-apart from DMARDscommonly linked to neutropaenia, ${ }^{18}$ or had a diagnosis of solid or haematological malignancy. Neutropaenia occurred at a median (range) of $12(0-120)$ months after the RA diagnosis; in $5(8.6 \%)$ of these patients, it was present at the baseline visit. The majority of patients had mild neutropaenia (grade $1: \mathrm{n}=42(72.4 \%)$; grade

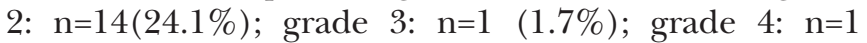
$(1.7 \%)$ ), with a mean \pm SD number of neutrophils of $1.69 \pm 0.3 \times 10^{\wedge} 9 / \mathrm{L}$ across all patient episodes.

\section{Laboratory and clinical features associated with neutropaenic episodes}

At the time of the neutropaenic episode $(\mathrm{n}=77)$, coexistent leucopaenia was found in $48(62.3 \%)$, lymphopaenia in $8(10.4 \%)$, thrombocytopaenia in $1(1.3 \%)$ and anaemia in $21(27.3 \%)$. None of the patients had lymphocytosis (lymphocytes $>4.0 \times 10^{\wedge} 9 / \mathrm{L}$ ). At the time of neutropaenia, most patients were in remission $(47.4 \%$, DAS28 <2.6) or had low disease activity $(18.6 \%$, DAS28
$<3.2)$, while only a few had moderate $(22.4 \%$, DAS28 $>3.2$ and $\leq 5.1)$ or high $(10.2 \%$, DAS28 $>5.1)$ disease activity.

\section{Comparing baseline characteristics and identifying possible predicting factors}

Patients who developed neutropaenia were more likely to be female $(p=0.01)$ and non-smokers $(p=0.007)$, compared with those who did not (table 1). Age, alcohol consumption, baseline DAS28 and seropositivity were not significantly different between the groups.

Baseline neutrophil levels were also significantly lower in patients who subsequently developed neutropaenia compared with those who did not (mean \pm SD: $4.294 \pm 2.116$ vs $5.891 \pm 2.153$, $\mathrm{p}<0.0001)$. Further analysis revealead that baseline neutrophil counts were significantly higher in smokers compared with non-smokers $($ mean \pm SD: $6.382 \pm 2.356$ vs $5.548 \pm 2.110, \mathrm{p}<0.0001)$ and in men compared with women (mean \pm SD: $6.116 \pm 2.274$ vs $5.571 \pm 2.143, \mathrm{p}=0001)$. Also, men were more likely to be smokers compared with women $(32.9 \%$ vs $21.1 \%$, $\mathrm{p}<0.0001)$. Correction for multiple comparisons did not affect the statistical significance of any of the abovementioned values. There were no significant differences in baseline counts of total white cells, lymphocytes, platelets or haemoglobin (table 1). Binary logistic regression analysis confirmed baseline neutrophil levels as a negative predictor of neutropaenia development $(\mathrm{p}=0.001, \mathrm{~B}$ : $-0.491)$. None of the possible interactions checked were found to affect our model (gender by smoking status, 
Table 2 Cytopaenias observed, treatment received and infections rate throughout the follow-up time

\begin{tabular}{|c|c|c|c|}
\hline $\begin{array}{l}\text { Patient characteristics throughout the } \\
\text { disease }\end{array}$ & $\begin{array}{l}\text { Neutropaenic } \\
\mathrm{n}=58\end{array}$ & $\begin{array}{l}\text { Non-neutropaenic } \\
\mathrm{n}=713\end{array}$ & $P$ values \\
\hline \multicolumn{4}{|l|}{ Laboratory } \\
\hline Anaemia, ${ }^{*} \mathrm{n}(\%)$ & $25(43.1)$ & $210(29.5)$ & 0.04 \\
\hline Thrombopenia, $† \mathrm{n}(\%)$ & $1(1.7)$ & $5(0.70)$ & 0.375 \\
\hline Leucopaenia,ł n (\%) & $41(70.7)$ & $23(3.43)$ & $<0.0001$ \\
\hline Lymphopaenia,§ n (\%) & $13(22.4)$ & $98(13.7)$ & 0.08 \\
\hline \multicolumn{4}{|l|}{ Treatment } \\
\hline Methotrexate, n (\%) & $52(89.6)$ & $590 / 667(88.4)$ & 1.000 \\
\hline Sulfasalazine, n (\%) & $33(56.9)$ & $342 / 667(51.2)$ & 0.494 \\
\hline Hydroxychloroquine, n (\%) & $31(53.4)$ & $345 / 667(51.7)$ & 0.891 \\
\hline Leflunomide, n (\%) & $3(5.2)$ & $43 / 667(6.4)$ & 1.000 \\
\hline Azathioprine, $\mathrm{n}(\%)$ & $1(1.7)$ & $3 / 667(0.5)$ & 0.281 \\
\hline Prednisone oral, n (\%) & $4(7.0)$ & $67 / 667(10.0)$ & 0.644 \\
\hline Corticosteroids intramuscularly, $\mathrm{n}(\%)$ & $48(82.8)$ & $573 / 667(80.3)$ & 0.559 \\
\hline Antitumour necrosis factor, $\mathrm{n}(\%)$ & $5(8.6)$ & $30 / 667(4.5)$ & 0.189 \\
\hline Abatacept, n (\%) & $0(0.0)$ & $3 / 667(0.5)$ & 1.000 \\
\hline Tocilizumab, n (\%) & $0(0.0)$ & $11 / 667(1.7)$ & 1.000 \\
\hline Rituximab, n (\%) & $0(0.0)$ & $10 / 667(1.5)$ & 1.000 \\
\hline \multicolumn{4}{|l|}{ Outcomes } \\
\hline Infections, incidence rate $(95 \% \mathrm{Cl})$ ๆ & 4.43 (1.62 to 9.66$)$ & 3.87 (2.92 to 5.04$)$ & 0.878 \\
\hline
\end{tabular}

*Haemoglobin $<135 \mathrm{~g} / \mathrm{L}$ for men and haemoglobin $<120 \mathrm{~g} / \mathrm{L}$ for women.

†Platelets $<100 \times 10^{\wedge} \mathrm{g} / \mathrm{L}$

†White cell count: $<4 \times 10^{9} / \mathrm{L}$.

§Lymphocytes: $<1 \times 10^{9} / \mathrm{L}$.

IIncidence rate is expressed as events per 1000 person-months.

$\mathrm{p}=0.515$; baseline neutrophils by smoking status, $\mathrm{p}=0.175$; gender by baseline neutrophils, $\mathrm{p}=0.426$ ). Furthermore in a regression analysis having only gender and smoking status as covariates, it was found that both male gender ( $\mathrm{p}=0.027, \mathrm{~B}:-0.764)$ and smoking $(\mathrm{p}=0.018, \mathrm{~B}:-1.042)$ were negatively associated with neutropaenia development. Additionally, compared with those with grade 1 or grade 2 neutropaenia (online supplementary table 2), patients with grade $3 / 4$ neutropaenia (analysed as one group because of the small number of patients in each of these two groups) were older $(\mathrm{p}=0.02$ and $\mathrm{p}=0.04$, respectively) and had higher DAS28 at baseline visit ( $\mathrm{p}=0.018$ and $\mathrm{p}=0.026$, respectively).

\section{Comparing characteristics throughout the disease course}

During the total follow-up time, patients who developed at least one episode of neutropaenia were also more likely to develope anaemia $(\mathrm{p}=0.04)$ at some time point, but not other blood count abnormalities (table 2). Characteristics or treatment received throughout the disease course did not differ among patients with different grades of neutropaenia (online supplementary table 2).

\section{DMARDs and steroids}

Treatment received for RA did not differ significantly between those with or without neutropaenia throughout the disease course (table 2). The frequency of neutropaenia for the total number of patients with RA in our cohort receiving methotrexate, sulfasalazine and hydroxychloroquine was $8.1 \%, 8.8 \%$ and $8.2 \%$, and the respective rates were $4.92,6.68$ and 5.69 per 1000 personsmonths. Considering all episodes of neutropaenia $(\mathrm{n}=77), 76.4 \%$ were on methotrexate (median (range) dose: 17 (5-25) $\mathrm{mg} /$ week, median (range) exposure time: 7.7 (0.5-48.0) months), $47.2 \%$ were on sulfasalazine (median (range) dose: $2(0.5-3) \mathrm{g} /$ day, median (range) exposure time: 12.0 (1.4-48) months) and 44.4\% were on hydroxychloroquine (median (range) dose: 200 (200-400) mg/day, median (range) exposure time: 24.0 (0.9-48.0) months). In $30.6 \%$ and $19.4 \%$ of the episodes, patients were on combination treatment with 2 and 3 conventional DMARDs, respectively. Episodes of neutropaenia led to treatment discontinuation of the current DMARD in $18.1 \%$ of cases (14 out of 77 ). Sulfasalazine was stopped permanently in five cases, while methotrexate was stopped in nine patients (only temporarily in five). No adjustment in treatment was made for patients on hydroxychloroquine. No statistically significant difference was observed in the occurrence of subsequent neutropaenic episodes when we compared patients in whom treatment with methotrexate and/or sulfasalazine was permanently or temporarily discontinued after the episode of neutropaenia with those who did not have any 
treatment adjustments for methotrexate $(\mathrm{p}=0.423)$ and for sulfasalazine $(\mathrm{p}=0.304)$.

The majority ( 37 of $58 ; 63.8 \%$ ) of patients who developed neutropaenia had received intramuscular steroids (either triamcinolone or methylprednisolone) by the time of the first episode of neutropaenia. Of these, 18 $(48.6 \%)$ had received only one injection, 13 (35.1\%) had received two, while $6(16.2 \%)$ had received more than two intramuscular injections. The mean $( \pm$ SD $)$ time interval between the last intramuscular steroid injection and the episode of neutropaenia was $431.2( \pm 309.9)$ days, and the mean $( \pm \mathrm{SD})$ cumulative dose of steroids received by intramuscular injection prior to the neutropaenia episode was $101.5( \pm 84.1) \mathrm{mg}$ for triamcinolone and $198.8( \pm 121.0) \mathrm{mg}$ for methylprednisolone.

In patients who developed neutropaenia, the mean cumulative dose of intramuscular steroids received throughout the disease course (mean $\pm \mathrm{SD}$ : triamcinolone $133.8 \pm 36.6 \mathrm{mg}$; methylprednisolone $230.0 \pm 157.0$ $\mathrm{mg}$ ) did not differ compared with that of patients who never developed neutropaenia (mean \pm SD: triamcinolone $144.7 \pm 130.1 \mathrm{mg}, \mathrm{p}=0.979$; methylprednisolone $243.5 \pm 157.4 \mathrm{mg}, \mathrm{p}=0.718$ ). The percentage of patients who received intramuscular steroids throughout the disease course was also comparable between the two groups (neutropaenic: 48 of $58(82.8 \%)$; non-neutropaenic: 573 of 667 (80.3\%); $\mathrm{p}=0.559)$.

Only four of the patients who developed neutropaenia had been exposed to oral steroids. None of them were receiving oral steroids at the time of neutropaenic episode, with a mean $( \pm \mathrm{SD})$ time interval between the discontinuation of steroids and the episode of neutropaenia of $240( \pm 143.1)$ days. Comparison with patients who never developed neutropaenia did not reveal any differences in mean exposure time to steroids (mean \pm SD: for neutropaenic: $82.5 \pm 9.6$ days; for non-neutropaenic: $90.7 \pm 41.1$ days; $p=0.118$ ) or in percentage of patients who had received steroids by mouth throughout the disease course (neutropaenic: 4 of 58 (7.0\%); non-neutropaenic: 67 of 667 (10.0); $p=0.644)$. Most of them were exposed to tapering high/medium steroid doses. Percentages were comparable between the two groups (high/medium steroid doses for neutropaenic: $75 \% / 25 \%$; for non-neutropaenic: $73.1 \% / 19.4 \%$; $\mathrm{p}=1.000$ ).

\section{Natural history and outcomes}

The majority (44 of $58 ; 75.8 \%$ ) of patients with neutropaenia had only a single episode (transient neutropaenia) recorded. Compared with patients with transient neutropaenia, those with recurrent episodes were found to have more frequent baseline anaemia $(\mathrm{p}=0.03)$. No other demographic, clinical or laboratory feature, at baseline or throughout the disease course, was found to differ significantly between the two groups.

Infections were found in temporal association (within 3 months prior to or after the episode of neutropaenia) with neutropaenia in three cases $(3.9 \%)$. The rate of infections per 1000 person-months did not differ between patients who developed neutropaenia and those who did not ((95\% CI), 4.43 (1.62 to 9.96$)$ vs 3.87 (2.92 to 5.04); $\mathrm{p}=0.878$ ). The rate of infections was also comparable between patients with transient or recurrent neutropaenia ( $(95 \% \mathrm{CI}), 3.07$ (0.62 to 9.02$)$ vs 7.89 (1.58 to 23.1), respectively; $\mathrm{p}=0.443$ ) and between patients with different grades of neutropaenia $((95 \% \mathrm{CI})$, grade 1 : 5.07 (1.63 to 11.83); grade 2: 2.92 (0.04 to 16.7); grade 3 - 4: not applicable, $\mathrm{p}=1.000$ ) (online supplementary table 2).

\section{DISCUSSION}

Neutropaenia is a recognised finding in patients with $\mathrm{RA}$, but its true incidence is not well defined, particularly in early RA. Its pathogenesis can be multifactorial, with several mechanisms proposed, namely (1) autoimmune neutropaenia in the context of RA where antigranulocyte antibodies are sometimes present, (2) bone marrow failure, (3) Felty's syndrome, (4) large granulocytic lymphocyte leukaemia, (5) viral infections and (6) medications. $^{6}$

Herein, we estimated the frequency of neutropaenia in patients with newly diagnosed RA who were DMARDnaive at recruitment (baseline) and treated in line with standard clinical practice. It was found that $7.5 \%$ of patients with RA developed at least one episode of neutropaenia during follow-up (median 18 months). Our results are also consistent with previous cohorts where neutropaenia in untreated patients with RA was found to be very low: $-0.65 \%$ of patients in our cohort had neutropaenia at baseline. ${ }^{2}$

In line with previous studies which reported low neutrophil counts in about $2 \%-10 \%$ and $1.8 \%-12.5 \%$ of patients treated with sulfasalazine $e^{111219}$ and methotrexate,,$^{81420}$ respectively, in our cohort this frequency was found to be about $8 \%$ for each drug. The median exposure time to these drugs, in patients who developed neutropaenia, in our study was more than 6 months, suggesting, as previously reported, that neutropaenia occurrence was not always an immediate effect of the medication received. $^{78}$ Sulfasalazine or methotrexate was temporarily or permanently discontinued in about $20 \%$ of cases of neutropaenia in our study. Prednisone is recognised to increase leucocyte, and particularly neutrophil, count by a number of potential mechanisms. ${ }^{21-23}$ However, in our study treatment with oral or intramuscular steroids did not affect the occurrence of neutropaenia, with comparable steroid exposure and doses between patients who developed neutropaenia and those who did not.

Although there are no studies specifically designed to explore this, methotrexate and sulfasalazine are drugs thought to be most associated with increased neutropaenia occurrence in RA. ${ }^{6824}$ In fact, in a large study analysing the computer records of patients with RA who were on monotherapy with DMARDs, neutropaenia was found to be equally common for these two drugs. ${ }^{8}$ The existing DMARD guidelines suggest to monitor blood 
regularly (every 2-4 weeks for the first 1-3 months and then less frequently (eg, every 4-12 weeks)) ${ }^{25-27}$ Guidelines on prescription and monitoring of non-biologic DMARDs generally advise that the perscriber-if this is different from the treating clinician-should contact the rheumatology team and consider treatment discontinuation if neutrophils drop below $1.600 / \mu \mathrm{L}$ or the total white cell count is below $3.500 / \mu \mathrm{L} .{ }^{25}$ In previous guidelines it was also suggested not to start methotrexate or leflunomide in patients whose white cell counts are below $3.000 / \mu \mathrm{L}^{28}$

Published reports for neutropaenia with biologic drugs range from $14.3 \%$ to $19 \% .{ }^{134}$ However, for some, such as rituximab, this association may be difficult to assess due to delayed onset of neutropaenia following treatment. ${ }^{29}{ }^{30}$ In our cohort, the small percentage of patients treated with biologics precluded further analysis about the possible association between neutropaenia and exposure to biologics. There were no patients on Janus Kinase (JAK) inhibitors. While neutropaenia may be anticipated based on their biologic action, ${ }^{31}$ data available from longterm extension studies suggest that this is encountered in only about $5 \%$ of patients and is mainly of grade $1 .{ }^{32} 33$

Interestingly, patients who developed neutropaenia in our cohort were more likely to have anaemia, but not other cytopaenias, throughout the disease course. Furthermore, patients with recurrent neutropaenia were more likely to have baseline anaemia, compared with those who only had a single recorded occurrence of neutropaenia. This could suggest that bone marrow suppression may be a contributing factor. However, bone marrow studies were not performed or required in any of these patients, so this cannot be confirmed. That said, there is a growing literature describing the inflammatory context of the RA bone marrow, ${ }^{345}$ and future studies to explore these mechanisms are warranted.

Further analysis comparing patients with different grades of neutropaenia suggested that patients with more severe neutropaenia (grade 3/4) were more likely to be older and have higher disease activity at baseline visit. This analysis has to be interpreted with caution, as the group of patients with grade $3 / 4$ neutropaenia included only two patients in this cohort. These results could be partially explained by the fact that older people-especially in the context of an autoimmune rheumatic disease-seem to be more prone to develop neutropaenia. ${ }^{24}$ Various factors have been proposed to contribute to this increase with age, including comorbidities, bone marrow suppression and aberrant drug metabolism. ${ }^{24}$

This study also attempted to identify possible predictors for the development of neutropaenia. We found that women, non-smokers and those with lower baseline neutrophil counts were more likely to develop neutropaenia. A positive relationship between smoking and increased numbers of white cells and/or neutrophils has been reported previously ${ }^{36}{ }^{37}$ and was also observed in our cohort, with higher baseline neutrophil counts in smokers compared with non-smokers. Also, in our cohort men were more likely to be smokers and to have higher baseline neutrophil counts. Thus, it might be possible that the observed association between non-smoking, female gender and the development of neutropaenia is confounded by non-smokers' lower baseline neutrophil levels. Interactions between the aforementioned factors did not affect the binary logistic regression analysis, which confirmed only baseline neutrophil levels as predictor for subsequent neutropaenia development. On the other hand, a regression analysis with only male gender and smoking status as independent variables suggested that both are negatively associated with neutropaenia occurrence. These findings are consistent with studies in the oncology literature suggesting that smoking might act as a protective factor for chemotherapy-induced neutropaenia, which has been attributed to the possible epigenetic effects of smoke on cytochrome P450 enzymes. ${ }^{38-40}$ Furthermore, there is also some evidence from oncology studies that female gender may be a risk factor for neutropaenia development. ${ }^{414}$ Therefore, the possible association of smoking and male gender with reduced frequency of neutropaenia in RA warrants further investigation.

Reassuringly, neutropaenia in the context of early RA was not associated with a significantly increased rate of infections, most probably reflecting the fact that neutropaenia in our cohort was mostly mild. However, it should be noted that a possible difference in the frequency of infections could be missed as a result of the small number $(n=58)$ of patients with at least one episode of neutropaenia.

We acknowledge that our study has certain limitations. First, it is possible that episodes of neutropaenia have been missed between the 6-monthly visits. Although this timing reflects the real-world practice for some patients with RA, the follow-up for early RA is more intense in clinical practice, and therefore the frequency of neutropaenia might have been underestimated in our cohort. Second, our cohort does not include many patients on biologic treatment, as it is an inception RA cohort. Thus, no conclusions can be made for neutropaenia in patients treated with biologic drugs. Third, the presence of antinuclear or other autoantibodies and certain important extra-articular manifestations (eg, sicca manifestations) were not recorded in our cohort. Therefore, occurrence of secondary autoimmune rheumatic diseases could not be defined. However, as described earlier, patients with existing alternative rheumatic diagnosis at baseline (eg, psoriatic arthritis, primary Sjogren's, systemic lupus erythematosus) were excluded, as were participants whose diagnosis was revised by their treating rheumatologist during the follow-up period.

In summary, in our cohort, while at least one episode of neutropaenia was recorded in $7.5 \%$ of patients with early RA, this was generally mild and was not associated with increased infections. The strongest predictor for the occurrence of subsequent neutropaenia was the baseline neutrophil level, while a possible protective role of smoking and male gender warrants further investigation. 
Contributors Conception or design of the work: GEF, MHD, IBM, DP, SS. Data collection: GEF, CP, AG. Data analysis and interpretation: GEF, CP, AG, MHD, IBM, DP, SS. Drafting the article: GEF, CP, AG, MHD. Critical revision of the article: IBM, DP, SS. Final approval of the version to be published: GEF, CP, AG, MHD, IBM, DP, SS.

Funding The SERA cohort was supported by joint funding from the Chief Scientist's Office (award ref ETM-40) and Pfizer.

Competing interests None declared.

Patient consent Not required.

Ethics approval The study was reviewed and approved by the West of Scotland Research Ethics Committee (Reference 10/S0704/20).

Provenance and peer review Not commissioned; externally peer reviewed. Data sharing statement № additional data are available.

Open access This is an open access article distributed in accordance with the Creative Commons Attribution Non Commercial (CC BY-NC 4.0) license, which permits others to distribute, remix, adapt, build upon this work non-commercially, and license their derivative works on different terms, provided the original work is properly cited, appropriate credit is given, any changes made indicated, and the use is non-commercial. See: http://creativecommons.org/licenses/by-nc/4.0/

\section{REFERENCES}

1. Hastings R, Ding T, Butt $S$, et al. Neutropenia in patients receiving anti-tumor necrosis factor therapy. Arthritis Care Res 2010;62:764-9.

2. Le Boëdec M, Marhadour T, Devauchelle-Pensec V, et al. Baseline laboratory test abnormalities are common in early arthritis but rarely contraindicate methotrexate: study of three cohorts (ESPOIR, VErA, and Brittany). Semin Arthritis Rheum 2013;42:474-81.

3. Rajakulendran S, Gadsby K, Allen D, et al. Neutropenia while receiving anti-tumour necrosis factor treatment for rheumatoid arthritis. Ann Rheum Dis 2006;65:1678-9.

4. Shovman O, Shoenfeld Y, Langevitz P. Tocilizumab-induced neutropenia in rheumatoid arthritis patients with previous history of neutropenia: case series and review of literature. Immunol Res 2015;61:164-8.

5. Hellmich B, Pinals RS, Loughran TP, et al. New clues to accrue on neutropenia in rheumatoid arthritis. Clin Immunol 2005;117:1-5.

6. Lazaro E, Morel J. Management of neutropenia in patients with rheumatoid arthritis. Joint Bone Spine 2015;82:235-9.

7. Farr M, Symmons DP, Blake DR, et al. Neutropenia in patients with inflammatory arthritis treated with sulphasalazine. Ann Rheum Dis 1986;45:761-4.

8. Grove ML, Hassell AB, Hay EM, et al. Adverse reactions to disease-modifying anti-rheumatic drugs in clinical practice. QJM 2001;94:309-19.

9. Gutierrez-Ureña S, Molina JF, García CO, et al. Pancytopenia secondary to methotrexate therapy in rheumatoid arthritis. Arthritis Rheum 1996;39:272-6.

10. Kivity S, Zafrir Y, Loebstein R, et al. Clinical characteristics and risk factors for low dose methotrexate toxicity: a cohort of 28 patients. Autoimmun Rev 2014;13:1109-13.

11. Marabani M, Madhok R, Capell HA, et al. Leucopenia during sulphasalazine treatment for rheumatoid arthritis. Ann Rheum Dis 1989;48:505-7.

12. Marouf ES, Morris IM. Neutropenia in patients with rheumatoid arthritis, treated with sulphasalazine. Br J Rheumatol 1990;29:407-9.

13. Pamuk ON, Kisacik B, Pamuk GE, et al. Do impaired memory, cognitive dysfunction and distress play a role in methotrexaterelated neutropenia in rheumatoid arthritis patients? A comparative study. Rheumatol Int 2013;33:2631-5.

14. Rajakulendran S, Allen D, Deighton C. Should the monitoring of methotrexate and leflunomide be the same? Rheumatology 2005;44(Suppl 1):65

15. Dale J, Paterson C, Tierney A, et al. The Scottish Early Rheumatoid Arthritis (SERA) Study: an inception cohort and biobank. BMC Musculoskelet Disord 2016;17:461

16. Aletaha D, Neogi T, Silman AJ, et al. 2010 Rheumatoid arthritis classification criteria: an American College of Rheumatology/ European League Against Rheumatism collaborative initiative. Arthritis Rheum 2010;62:2569-81.

17. Benjamini $Y$, Hochberg Y. Controlling the false discovery rate: a practical and powerful approach to multiple testing. J R Stat Soc 1995;57:289-300.

18. Moore DC. Drug-induced Neutropenia: a focus on Rituximabinduced late-onset Neutropenia. P T 2016;41:765-8.
19. Farr M, Tunn EJ, Symmons DP, et al. Sulphasalazine in rheumatoid arthritis: haematological problems and changes in haematological indices associated with therapy. Br J Rheumatol 1989;28:134-8.

20. White DH, Chapman PT, O'Donnell JL, et al. Lack of association between elevated mean red cell volume and haematological toxicity in patients receiving long-term methotrexate for rheumatoid arthritis. Intern Med J 2010;40:561-5.

21. Fay ME, Myers DR, Kumar A, et al. Cellular softening mediates leukocyte demargination and trafficking, thereby increasing clinical blood counts. Proc Natl Acad Sci U S A 2016;113:1987-92.

22. Nakagawa M, Terashima T, D'yachkova Y, et al. Glucocorticoidinduced granulocytosis: contribution of marrow release and demargination of intravascular granulocytes. Circulation 1998;98:2307-13.

23. Weber PS, Toelboell T, Chang LC, et al. Mechanisms of glucocorticoid-induced down-regulation of neutrophil L-selectin in cattle: evidence for effects at the gene-expression level and primarily on blood neutrophils. J Leukoc Biol 2004;75:815-27.

24. Yeoh SA, Fox C, Hull R. Neutropenia in the elderly: a rheumatology perspective. Drugs Aging 2016;33:585-601.

25. Ledingham J, Gullick N, et al. BSR and BHPR standards, guidelines and audit working group. BSR and BHPR guideline for the prescription and monitoring of non-biologic disease-modifying antirheumatic drugs. Rheumatology 2017;56:865-8.

26. Rigby WFC, Lampl K, Low JM, et al. Review of routine laboratory monitoring for patients with rheumatoid arthritis receiving biologic or nonbiologic DMARDs. Int J Rheumatol 2017;2017:9614241-.

27. Singh JA, Saag KG, Bridges SL, et al. 2015 American college of rheumatology guideline for the treatment of rheumatoid arthritis. Arthritis Rheumatol 2016;68:1-26.

28. Saag KG, Teng GG, American College of Rheumatology. American college of rheumatology 2008 recommendations for the use of nonbiologic and biologic disease-modifying antirheumatic drugs in rheumatoid arthritis. Arthritis Rheum 2008;59:762-84.

29. Monaco WE, Jones JD, Rigby WF. Rituximab associated late-onset neutropenia-a rheumatology case series and review of the literature. Clin Rheumatol 2016;35:2457-62.

30. Salmon JH, Cacoub P, Combe B, et al. Late-onset neutropenia after treatment with rituximab for rheumatoid arthritis and other autoimmune diseases: data from the Autolmmunity and Rituximab registry. $R M D$ Open 2015;1:e000034

31. Winthrop KL. The emerging safety profile of JAK inhibitors in rheumatic disease. Nat Rev Rheumatol 2017;13:320.

32. Schulze-Koops H, Strand V, Nduaka C, et al. Analysis of haematological changes in tofacitinib-treated patients with rheumatoid arthritis across phase 3 and long-term extension studies. Rheumatology 2017;56:46-57.

33. Wollenhaupt J, Silverfield J, Lee EB, et al. Safety and efficacy of tofacitinib, an oral janus kinase inhibitor, for the treatment of rheumatoid arthritis in open-label, longterm extension studies. J Rheumatol 2014;41:837-52

34. Jaworski J, Maslinski W, Pazdur J, et al. Decreased expression of integrins by hematopoietic cells in patients with rheumatoid arthritis and anemia: relationship with bone marrow cytokine levels. $J$ Investig Allergol Clin Immunol 2008;18:17-21.

35. Kuca-Warnawin E, Burakowski T, Kurowska W, et al. Elevated number of recently activated $T$ cells in bone marrow of patients with rheumatoid arthritis: a role for interleukin 15? Ann Rheum Dis 2011;70:227-33.

36. Higuchi T, Omata F, Tsuchihashi $\mathrm{K}$, et al. Current cigarette smoking is a reversible cause of elevated white blood cell count: cross-sectional and longitudinal studies. Prev Med Rep 2016;4:417-22.

37. Schwartz J, Weiss ST. Cigarette smoking and peripheral blood leukocyte differentials. Ann Epidemiol 1994;4:236-42.

38. de Graan AJ, Loos WJ, Friberg LE, et al. Influence of smoking on the pharmacokinetics and toxicity profiles of taxane therapy. Clin Cancer Res 2012;18:4425-32.

39. O'Malley M, Healy P, Daignault S, et al. Cigarette smoking and gemcitabine-induced neutropenia in advanced solid tumors. Oncology 2013;85:216-22.

40. van der Bol JM, Mathijssen RH, Loos WJ, et al. Cigarette smoking and irinotecan treatment: pharmacokinetic interaction and effects on neutropenia. J Clin Oncol 2007;25:2719-26.

41. Lambert LA, Armstrong TS, Lee JJ, et al. Incidence, risk factors, and impact of severe neutropenia after hyperthermic intraperitonea mitomycin C. Ann Surg Oncol 2009;16:2181-7.

42. Schwartzberg LS. Neutropenia: etiology and pathogenesis. Clin Cornerstone 2006;8(Suppl 5):S5-11. 